\title{
Factors Affecting Consumers' Preferences On Fast Food Items In Bangladesh
}

Nazrul Islam, East West University, Bangladesh

G. M. Shafayet Ullah, Southeast University, Bangladesh

\begin{abstract}
Fast food industry is a high growing sector of Bangladesh. It is concerned with the tastes and habits of the people. The food-taking habit especially in fast food segment has been changing very fast over last decade among the people of Dhaka - the capital city of Bangladesh. The reasons could be attributed by the increase of awareness, growth of education, development of information technology, and expansion of television channels and print media in Bangladesh. Hence, this paper aims at identifying the preference factors of fast food consumers living in Dhaka city. This study was conducted among the university students who usually eat fast food at their leisure time. To conduct the study, a total of 250 respondents were interviewed with a structured questionnaire. Both descriptive and inferential statistics were used in analyzing the data. Multivariate analysis technique like factor analysis was performed to identify the preference factors of the fast food student-consumers of Bangladesh. Multiple regressions were run to identify the relationship between the factors identified and the overall preference of the consumers. Results show that the consumers give most importance on brand reputation of the food item followed by nearness to receive and accessibility, similarity of taste with previous experience, cost and quality of the food, discount and taste, cleanliness and hygiene, salesmanship and decoration, fat and cholesterol level, and self-service factors. This study suggests that the brand reputation, nearness and accessibility, similarity in taste, and cost and quality relationship should be emphasized to improve the attraction of the university students towards the fast food items in Bangladesh.
\end{abstract}

Keywords: Fast Food Preferences, Brand Reputation, Similarity in Taste, Cost and Quality, Nearness and Accessibility.

\section{STATEMENT OF THE PROBLEM}

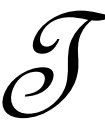

aking food is very important for the survival of human being. Food provides the necessary nutrition for the body of the human being that is indispensable. Due to the differences in culture, geographic locations, environment and climate, food items vary from society to society. Some may vary in terms of ingredients such as, soybean oil in Asia and palm oil in other continents. While some may vary in terms of presentation such as, food spread over banana leaves in India or on ceramic plates in other places. Whereas tastes of some food items may vary in processing or cooking such as, ovens in the West, gas/wood stove in the East. Eating methods are also different in many cases such as, using spoons and forks in the West as opposed to using chopsticks or hand in the East. New types of food items are also available in the different parts of the world on which people have attraction. One such type of food is fast food.

Fast food is an important item of the people as it is readymade in nature and easy to eat. The term "Fast food" was recognized in a dictionary by Merriam-Webster in 1951. According to Merriam-Webster, fast food is the term given to food that can be prepared and served very quickly. Generally, any meal with low preparation time can be considered as fast food. But typically the term refers to the foods sold in a restaurant with low preparation time and served to the customer in a packaged form for take-away. Fast foods are mostly designed for ready availability, use and consumption ${ }^{1}$. Fast foods are different from convenient ready-to-eat-on-the-go confectionary items i.e. cakes, biscuits, breads etc. snack items such as, potato chips, candies, peas etc. and the fruit items. Examples of most 
prominent fast food items include burger, pizza, fried chicken, hamburger and sandwich. Fast food restaurants are also known as Quick Service Restaurants (QSR's) and fast foods are often termed as Food Away From Home (FAFH).

The habit of taking fast food also varies from society to society. In Bangladesh, the habit of taking fast food is changing very fast. People who are living in the city have high tendency to consume fast food compared to the people living in the rural areas. The reason for the change is the time factor. They do not have much time to prepare food at their home. As society develops, the economic activities also expand. Therefore, people become busy and that discourages them to prepare food at their home. As such, the only alternative is to consume food that is prepared by others and preferably light in nature. While people select fast food, a number of factors are considered by them. Hence, this study was designed to identify the factors related to the preferences of the consumers of fast food in Bangladesh. This study only includes the university student consumers of fast food. The main objective of this study is to study and develop a consumer behavioral profile for the fast-food selection in Bangladesh. The specific objectives are outlined below.

i. $\quad$ To give an overview of the fast food industry of Bangladesh.

ii. To identify the factors related to the consumer preferences of the fast food products.

iii. To find out the group and situational influences that affect the selection of fast food.

iv. To explore the criteria the consumers use for selecting fast food.

v. To provide suggestions to the sellers and the policy makers of fast food industry.

\section{RATIONALE OF THE STUDY}

The study on fast food is a new field of research. The outcome of the study is the identification of the factors influencing the student-consumers of fast food products in Bangladesh. The global fast food business has been discussed. The study also creates interest for the fast food consumers to know the selection model of the Bangladeshi consumers. Today's business is all about delighting consumers, and fast food sellers can achieve it by knowing what the consumers want or think beforehand. From the sellers' perspective, this study provides a unique opportunity to have a glance for making decision for fulfilling the needs of their target consumers. The findings of this paper would be useful to them to improve the quality of the overall fast food business. The findings of this paper will also provide fast food business a competitive edge over their competitors.

\section{FAST FOOD CONSUMPTION IN THE WORLD}

The first fast food restaurants were originated in the United States with White Castle in $1916^{2}$. Today, American-founded fast food chains such as McDonald's, KFC and Pizza Hut are multinational corporations with outlets across the globe ${ }^{3}$. Fast food restaurants represent one of the largest segments of the food industry with over 200,000 restaurants and $\$ 120$ billion in sales in the U.S. alone ${ }^{4}$. Some of the largest players in this category include international giants like McDonald's and Yum! Brands (Pizza Hut, KFC). International chains maintain a considerable presence outside the United States. Usually, relying on a franchise system, large international players have performed much more strongly than their domestic and regional competitors. International chains including McDonald's and Yum! Brands have 65 percent and 50 percent of their sales overseas respectively ${ }^{5}$. This indicates that fast food has a great demand all over the world.

The impact of McDonald's on the nation's culture of USA, economy and diet is not easy to ignore. About one-quarter of the adult population of the United States visits a fast food restaurant in a day. Americans' expenditure on fast foods is more than their expenditure on higher education, personal computers, software or new cars. They spend more on fast food than on movies, books, magazines, newspapers, videos and recorded music - combined ${ }^{6}$. The global fast food market grew by 4.8 percent in 2006 to reach a value of $\$ 102.7$ billion and in 2011 . The global fast food market is forecasted to have a value of $\$ 125.4$ billion, an increase of 22.2 percent over $2006^{7}$. Moreover, according to the United States Department of Agriculture (USDA), FAFH increased from 33 percent of total food expenditures in 1970 to 47 percent by 2003, with most occurring at table service and fast food restaurants (Binkley, 2008). 
A rapid rise has been observed in the number of western fast food chains. It is increasingly spreading out into smaller towns with significant implications for urban diets. The observed growth in fast food chains does not derive only from multi-national corporations, such as McDonald's, but also from domestic firms which are copying the products and operational procedures of their foreign competitors (Pingali and Khwaja, 2004). While the presence of large retail outlets and fast-food chains respond to consumer demand for their products, they also influence the dietary patterns in developing countries. Studies show that about 75 percent of a person's daily requirement for salt may be provided in one processed meal purchased from a retail outlet.

In light of the discussions above, it is clear that the fast food industry has been experiencing fast growth all over the world. But the growth rate has seen a significant decline over the past couple of years reflecting the maturity of the industry. This stagnation has been caused by several factors such as over saturation, slowing economy, anti-westernization, the rise of fast casual restaurants, and obesity. The various players have been trying to combat the losses due to over saturation, anti-westernization. But obesity remains as the greatest threat to the long term future of the industry as it continues to come under fire for offering high calorie food that lacks nutrition.

\section{FAST FOOD INDUSTRY IN BANGLADESH}

Fast food culture was started in the early nineties. In Bangladesh it has mainly geared towards the younger end of the market and the employees of the corporate sector. The fast food culture in Bangladesh has taken the country by storm. The first fast food shop started its business in the Bailey road of Dhaka. After that, a number of fast food shops started to grow exponentially in different places of the Dhaka city. Local entrepreneurs are leaders in pioneering the fast food industry of Bangladesh. New brands i.e. Swiss, Helvetia etc. are to name of some Bangladeshi fast food shops formed in franchising system. In early 2000, Bangladesh experienced the entry of the first international brand of fast food franchise in the country. Pizza Hut and KFC entered into Bangladeshi market having franchise with Transcom Foods Limited (TFL). Both Pizza Hut and KFC are subsidiaries of the world's largest restaurant company Yum! Restaurants International. TFL has opened three Pizza Huts and three KFC outlets in Bangladesh in a span of five years. Pizza Hut opened its flagship restaurant in 2003 at Dhaka. Following its grand success in Dhaka, the Chittagong outlet was opened in 2005. The third Pizza Hut restaurant was launched in Dhaka in 2008. Meanwhile, Kentucky Fried Chicken (KFC) perceived as high-quality fast food in a popular array of complete meals to enrich the consumer's everyday life. TFL successfully launched the flagship KFC in 2006 and gained attention of the people with its taste, high standard of hygiene, cleanliness, interior attractiveness, affordable pricing etc. Following its enormous success in Dhaka, the second and third outlets were opened in $2008^{8}$.

There were two major shakeups in the fast food industry in Bangladesh. In September 2005, the government of Bangladesh started a major drive against the companies that were found adulterating fruits, using pesticides, unauthorized food colors and food items that expired their date of uses etc. These drives created a serious impact on the public health sector of Bangladesh. Many renowned restaurants and fast food shops were found guilty and those were highly publicized in press and media. This lead towards the mistrust of the common people and resulted in temporary decline of sale of fast food items. Due to this shakeup, many middle and small fast food shops were closed and only a few restaurants, mostly the expensive and franchise ones, were left. This caused heavy losses following surprise raids by mobile courts. The normal buzzing snack shops at Dhaka no longer draw the same attraction after September 2005. The mobile courts raided and as a result almost 60 percent of business was declined. A big portion of the customers at these shops were teenagers and students. Many of which had stopped going to the snack shops following the news reports of stale items being sold.

According to some owners of fast food shops in Dhaka city, the charges the officials of mobile courts made based on a bringing process which was completely unfair ${ }^{9}$. The fast food consumers were shocked as the mobile court team sent out to stop food adulteration and contamination in eateries and processed-food factories around the city $^{10}$. The mobile court operations also expanded to other cities like Chittagong and Khulna outside the capital afterwards $^{11}$. Sales in Dhaka city's fast food shops took a further fall as customers continued to ignore chicken items due to bird flu fear, hitting hard the booming fast-food business in Bangladesh. ${ }^{12}$ However, at present this situation has been substantially improved and the industry is in a good shape and growing again. 


\section{CONSUMERS' PREFERENCES ON FAST FOOD}

Consumers' preferences on fast food are very strong in some societies. This is because of the parallel changes in working and social life and habits of dining out. In social context, gradually the numbers of working families are increasing worldwide (Stamoulis, Kostas G. et al., 2004). This allows the families less time to cook and eat at home. Now, we need to socialize with people around us, colleagues and friends, neighbors more than before for business or social purposes. The customs today are to do the socialization over some food items away from home. Due to shortage of time, many modern nuclear families tend to prefer convenient, quick meals to rather traditional long meals. Here nuclear family refers to the type of family consisting of only husband, wife and one to two children. Today people prefer to have dinner in front of TV with the family members than to have dinner in the dining table. Moreover, more and more families tend to hold programs i.e. birthdays, anniversaries, other special occasions etc. out of home. Influences on the choice to dine out include insufficient time to cook at home, opportunities to socialize or conduct business, convenience or the need for a quick meal, enjoyment and family outings or celebrations (birthdays, anniversaries and other special occasions). Such changes in dining habits have led restaurants and other dining-out units to offer a great variety of foods and beverages providing customers with many more choices. This has encouraged people not to cook at their homes.

Urbanization also has significantly influenced the consumption of fast foods by the people. Projections show that the urbanization rates will increase between 2000 and 2030 relative to that of the past 30 years. The urban population, estimated at about 2.9 billion in 2000, is projected to reach 4.9 billion by 2030 . Most of the increase will be in the cities of developing countries. The population of which is expected to increase from 1.9 billion people in 2000 to about 3.9 billion people by 2030 (UNFPA, 2001). This change will account for almost the entire increment in developing countries' population growth. The comprehensive picture of a rapidly urbanizing world covers up large regional differences. As a result, urbanization will proceed gradually in many developed and transition countries in future where the vast majority of the population is already living in urban areas. At the other end of the scale are sub-Saharan Africa and Asia, where urban populations will be growing at an astonishing rate of nearly 5 percent per year (Stamoulis, Kostas G. et al., 2004). The projection is shown in Figure 1.

Figure 1: Urbanization Trends in the World

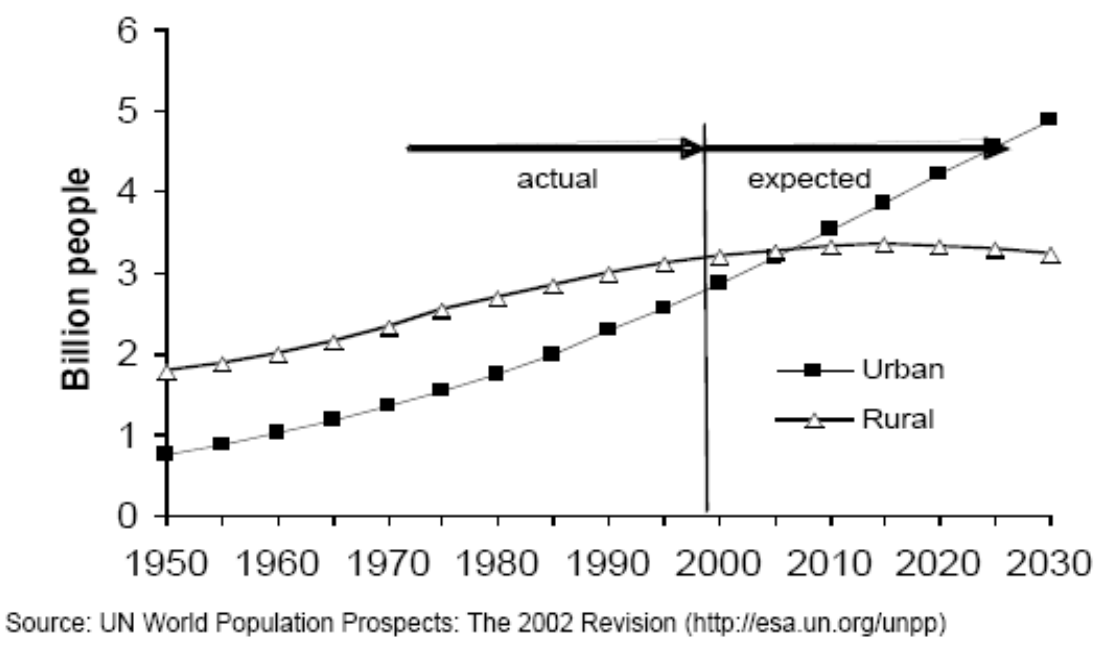

Urbanization is also accompanied by changes in habitual dietary practices and food consumption patterns. Important forces driving the differences between rural and urban diets are the higher average wages, opportunity cost of time in urban areas and the higher participation of women in the labor force. Other determinants of the structure of diets in urban areas include demographic factors, the organization of food markets, and the lower relative prices of processed foods relative to staples in urban areas. 
All factors mentioned above induce a move away from traditional time-consuming food preparation towards precooked and convenience food at home but also fast food, snacks, and street foods for outside meals. Evidence shows that following internal migration from rural to urban areas, the shift in the dietary pattern that leads to marked changes in the intakes of sugar, salt and fat by urban populations is related to the length of stay in urban areas. This has been influenced very strongly by the access to mass media such as television. Urban diets are higher in fat content, higher in sugar and salt content, and contain higher amounts of meat and dairy products than rural ones and contain lower amounts of fiber and higher intakes of alcohol (Popkin, 2002). The trend towards FAFH is also strong among the poorest segments of urban populations. Empirical evidence shows that smaller and poorer households have higher expenditure shares on prepared street foods. Data from an Accra-wide survey show that households in the lowest income quartile consumed 31.4 percent of their caloric intake away from home, more than any other income group (Maxwell et al. 1998). Mostly for the urban underprivileged, the shift towards fast and convenience foods is also a shift away from fresh fruits and vegetables, pulses, potatoes etc. towards a diet with increasing consumption of sugar, salt and fat (Smil, 2000).

There is considerable evidence that the meals eaten in restaurants are generally of lower nutritional quality than meals eaten at home. That is mainly due to higher fat and calorie content (Lin, Guthrie, and Frazao, 1999). Fast foods are frequently linked to the epidemic of obesity. But there has been very little scientific appraisal of a possible causal role (Prentice, 2003). Consumption of fast food among children in the United States seems to have an adverse effect on dietary quality in ways that plausibly could increase risk for obesity (Bowman, et. al., 2004). Kuchler (2005) claims that promotion strategies by fast food companies are at least partly responsible for rising obesity rates and these claims are now common. Anyway, particular attention should be given on products targeted to young family members and adolescents (Prentice, 2003). A variety of fast foods are chosen by girls and young women of African and South Asian countries (Lawrence, J. M. et al., 2007). Many issues that affect the food choice of people who move to the UK are common within different ethnic groups. Richard's (2009) study considered only measurable attributes of fast food-nutritional profiles, vendor identity or the distance from a consumer's home. However, the study suggested that more detailed experimental analysis would be able to determine the effect of perceptual attributes on consumer demand as well. Specific qualities of taste, consumer self-esteem, the reputation of each restaurant and other non-measurables may be relevant to a comprehensive treatment of an attribute-based fast food model. As far as the factors are concerned, Clark and Wood (1998) comment on the basis of their evidence, that food quality and value appear to be the most significant restaurant attributes. Lewis (1981) considered five factors in this regard such as food quality, menu variety, price, atmosphere and convenience. Food quality was found to be the most important attribute influencing customers' selection of a restaurant. Auty (1992) undertook a study of customers' perceptions of restaurants and the way that they select a particular eating place. Food type and quality were the most frequently cited variables, regardless of the occasion for dining out, but image and atmosphere or style were critical in the final choice between restaurants serving a similar quality and type of food. Carey and Genevieve (1995) determined food quality to be the most important variable in restaurant choice. The five factors most commonly included in respondents' rankings were: (1) range of food; (2) quality of food; (3) price of food; (4) atmosphere; and (5) speed of service. In general, evidence from all these studies suggests that the more concrete factors play the most important role in the consumer's choice of a dining-out unit. Besides the factors related to the dining-out unit, those related to the customer's socio-cultural background are also influential in their dining-out behavior. For example, attitudes, social values, family influences, group influences, social class and cultural background are important in determining choice (Buttle 1986; Bareham 1995). During the past several decades, physical environment has become an important area in the study of hospitality and retail environment, with researchers beginning to study the influence of such physical environments of a restaurant or store environment on consumer behavior (Turley and Milliman, 2002). Based on the discussions made above, a conceptual framework for the preference factors can be developed for experiment which is shown in Figure 2. 


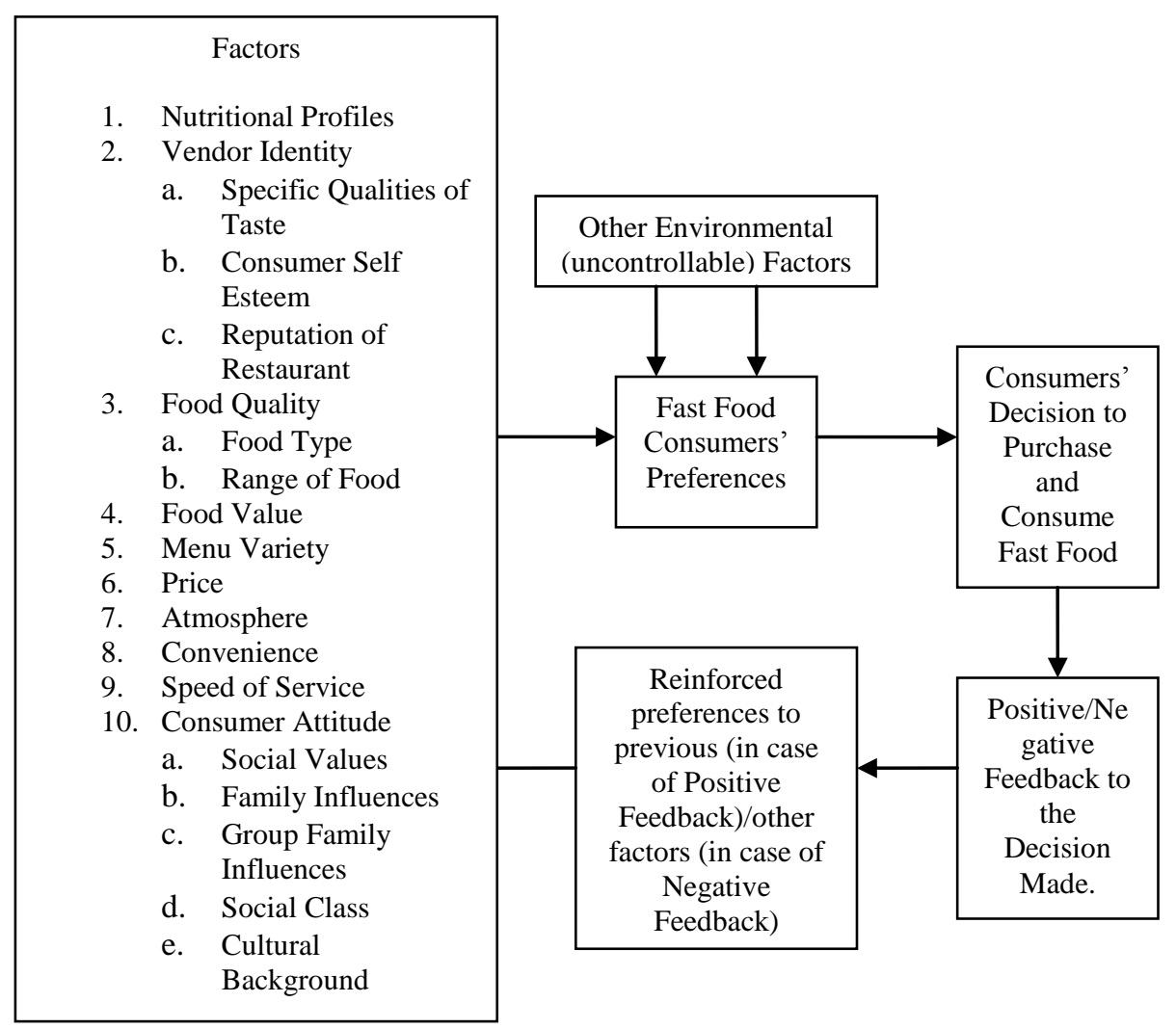

Figure-2: A Conceptual Model of Factors Influencing the Consumers of Fast Food

\section{RESEARCH METHODS}

This research selected the local fast food shops which were operating for a long time here in Bangladesh in the capital city of Dhaka. The fast food stores in Dhaka city mostly located in the Bailey road like the ancient Swiss, Capital, Bamboo Castle, Palki, Dahlia, Golpea, Euro Hut, Golden Food and Dominous pizza ${ }^{13}$. For this study, secondary data regarding the fast food industry of Bangladesh were collected. It was assumed that there were some forms of owner's association will be operating in the capital city- given the vast spread of the fast food shops. However, the observation shows that the major fast food shops in Dhaka do not have any fast food owners' association.

The main hypotheses of this study are that the fast food preferences of the university students are influence by the number of factors. The followings are specific hypotheses postulated based on literature review and tested in this study.

$\mathbf{H}_{1}$ : $\quad$ Brand Reputation determines the consumers' preference in consuming fast food

$\mathbf{H}_{2}$ : $\quad$ Nearness and Accessibility determine the consumers' preference in consuming fast food

$\mathbf{H}_{3}$ : $\quad$ Similar Taste of Fast Food determine the consumers' preference in consuming fast food

$\mathbf{H}_{\mathbf{4}}$ : $\quad$ Cost and Quality Relationship determine the consumers' preference in consuming fast food

H5: Discount and Taste determine the consumers' preference in consuming fast food

$\mathbf{H}_{6}$ : Clean and Hygiene determine the consumers' preference in consuming fast food

$\mathbf{H}_{7}$ : Salesmanship and Decoration determine the consumers' preference in consuming fast food

$\mathbf{H}_{\mathbf{8}}$ : $\quad$ Fat and Cholesterol determine the consumers' preference in consuming fast food

$\mathbf{H}_{9}$ : $\quad$ Self-Service determine the consumers' preference in consuming fast food 
Data were collected from various sources like national newspaper articles, international journals, scholarly articles, industry specific magazines, books related to the fast food industry. The primary data for this research were collected from the fast food consumers, specifically from the university students in Dhaka city through structured questionnaire. To conduct the study, a total of 250 respondents from different leading private universities were interviewed. The samples were selected using random sampling method. Five-point likert scales were used in designing the questionnaire. A total of 33 questions were used in the questionnaire to collect data from the respondents. Direct, one to one personal interviews were conducted among the university students to test their attitudes towards the choice of fast food items.

After collecting data, it was scrutinized and analyzed using SPSS 12.0. Both descriptive and inferential statistics were used in analyzing the data. Descriptive statistics such as simple percentage, mean, standard deviation, tabulation etc were used to describe the factors and the situation. Multivariate analysis like factor analysis was performed to identify the preference factors of the fast food consumers. Multiple regressions analyses were conducted to identify the relationship between the factors identified through factor analysis and the overall measure of preference of the respondents. Three regression analyses were conducted with the factors identified through factor analysis and the dependent variables. Three dependent variables were identified through literature review such as, (i) fast food energies the respondents (ii) fast food's are preferred when people are outside their homes, and (ii) fast food are good for lifestyle. Although there had been previous studies focusing on the preference factors of consumers of fast foods, no research had been conducted on the subject from the perspective of fast food consumers of Bangladesh. This paper indeed is the first of its kind. Not only the paper identifies the unique factors that influence the preferences of the consumers, but also it tries to explain the factors influence based on the current situation prevailing in the fast food industry of Bangladesh.

\section{ANALYSIS AND INTERPRETATIONS}

The results of this study were discussed primarily in two following sections such as, results of factor analysis and the results of regression analysis.

\subsection{The Results of Factor Analysis}

Factor analysis results show that the communalities of the variables are quite high, indicating that the variable used in the data set are highly cohesive in nature. The communality values of the variables are very high (Appendix 1). Factor analysis identified 9 factors that are related to the consumers' preferences related to fast food choice in Bangladesh. The total variance of the factors is 58.31 percent. From the Table 7.1 it can be concluded that the following 9 factors constitute 58.316 percent of the total variance. Brand reputation (13.626) is the most important factor to the fast food consumers in Bangladesh followed by nearness and accessibility (8.513), similar taste of fast food (7.77), cost and quality relationship (6.123), discount and taste (5.794), clean and hygiene (5.186), salesmanship and decoration (4.069), fat and cholesterol (3.832) and self-service (3.402).

Table 7.1 Factors related to Consumers' Preferences on Fast Food in Bangladesh

\begin{tabular}{|l|c|c|c|}
\hline \multicolumn{1}{|c|}{ Factors } & Eigenvalues & Percent of Variance & Cumulative percent \\
\hline 1. Brand reputation & 4.088 & 13.626 & 13.626 \\
\hline 2. Nearness and accessibility & 2.554 & 8.513 & 22.139 \\
\hline 3. Similar taste of fast food & 2.331 & 7.770 & 29.909 \\
\hline 4. Cost and quality relationship & 1.837 & 6.123 & 36.032 \\
\hline 5. Discount and Taste & 1.738 & 5.794 & 41.826 \\
\hline 6. Clean and Hygiene & 1.556 & 5.186 & 47.012 \\
\hline 7. Salesmanship and Decoration & 1.221 & 4.069 & 51.081 \\
\hline 8. Fat and Cholesterol & 1.150 & 3.832 & 54.914 \\
\hline 9. Self-service & 1.021 & 3.402 & 58.316 \\
\hline
\end{tabular}

Extraction Method: Principal Component Analysis. 
Brand reputation is number one factor used by the student consumers of fast food in selecting the item. This factor was constituted by the variables like reputation of the fast food shop for both new fast food and old fast food (Table 7.2).

Table 7.2: Brand Reputation of the Fast Food Item

\begin{tabular}{|l|c|}
\hline \multicolumn{1}{|c|}{ Variables } & Factor loading \\
\hline I will buy any fast food from well reputed fast food shops. & .763 \\
\hline I am willing to try new fast food items only from well reputed fast food shops. & .712 \\
\hline Even though I do not like the food, I like to go to the well reputed fast food shops. & .642 \\
\hline I prefer items from well known fast food shops than to little known fast food shops. & .621 \\
\hline
\end{tabular}

Nearness and accessibility is the second important factor of preference of taking fast food in Bangladesh by the university students (Table 7.3). Tables 7.4 to 7.10 are shown in appendices for the details of other factors.

Table 7.3: Nearness and Accessibility of the Fast Food Item

\begin{tabular}{|l|c|}
\hline \multicolumn{1}{|c|}{ Variables } & Factor loading \\
\hline I prefer the fast food shops that are close to my university. & .768 \\
\hline I prefer the fast food shops that are easily accessible from anywhere in Dhaka city. & .753 \\
\hline I prefer the fast food shops that offer privacy. & .659 \\
\hline
\end{tabular}

\subsection{Results of Regression Analysis}

Three regression analyses were conducted with the factors identified through factor analysis and three dependent variables. The dependent variables are (i) fast food energies the respondents (ii) prefers fast food when the people are outside their home and (ii) fast food are good for lifestyle. These relationships are discussed in the following sections.

\subsubsection{Fast Food Helps Energize University Students}

First regression analysis was run between the factors identified through factor analysis and the energy impact of fast food. The analysis revealed that the nine factors can explain up to 22.9 percent of the dependent variable $\left(\mathrm{R}^{2}=0.229\right)$. This indicates that the factors related to students' preferences have about 23 percent impact on the energy by fast food of the students (Table 7.11).

Table 7.11 Model Summary

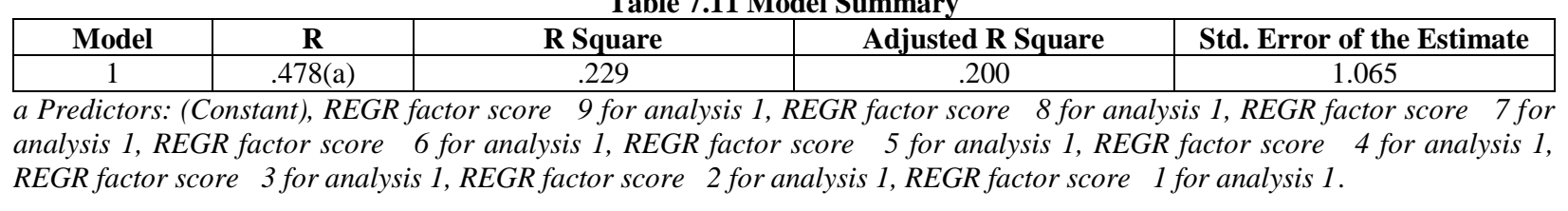

Table 7.12 shows that the preference factors related to the fast food choice of the students are as a whole significantly related to the overall energizing capacity of the fast food.

Table 7.12 ANOVA(b)

\begin{tabular}{|c|c|c|c|c|c|c|}
\hline Model & & Sum of Squares & df & Mean Square & F & Sig. \\
\hline 1 & Regression & 80.426 & 9 & 8.936 & 7.879 & $.000(\mathrm{a})$ \\
\hline & Residual & 271.076 & 239 & 1.134 & & \\
\hline & Total & 351.502 & 248 & & & \\
\end{tabular}

a Predictors: (Constant), REGR factor score 9 for analysis 1, REGR factor score 8 for analysis 1, REGR factor score 7 for analysis 1, REGR factor score 6 for analysis 1, REGR factor score 5 for analysis 1, REGR factor score 4 for analysis 1 , REGR factor score 3 for analysis 1, REGR factor score 2 for analysis 1, REGR factor score 1 for analysis 1

$b$ Dependent Variable: Fast food helps me to energize whenever I study. 
Table 7.13 shows that the factors like brand reputation, nearness and accessibility, similar taste of fast food, and cost and quality relationship are the significant factors. This means that the factors have significant relationship with the energy of the students gained by the fast food consumption.

Table 7.13 Coefficients (a)

\begin{tabular}{|l|c|c|c|c|c|}
\hline & \multicolumn{2}{|c|}{$\begin{array}{c}\text { Unstandardized } \\
\text { Coefficients }\end{array}$} & $\begin{array}{c}\text { Standardized } \\
\text { Coefficients }\end{array}$ & t & Sig. \\
\hline & B & Std. Error & Beta & & \\
\hline (Constant) & 2.815 & .067 & & 41.713 & .000 \\
\hline 1. Brand reputation & .151 & .068 & .127 & 2.234 & $.026^{*}$ \\
\hline 2. Nearness and accessibility & .302 & .068 & .254 & 4.468 & $.000^{*}$ \\
\hline 3. Similar taste of fast food & .322 & .068 & .271 & 4.763 & $.000^{*}$ \\
\hline 4. Cost and quality relationship & .296 & .068 & .248 & 4.370 & $.000^{*}$ \\
\hline 5. Discount and Taste & .056 & .068 & .047 & .834 & .405 \\
\hline 6. Clean and Hygiene & .029 & .068 & .025 & .432 & .666 \\
\hline 7. Salesmanship and Decoration & -.035 & .068 & -.029 & -.511 & .610 \\
\hline 8. Fat and Cholesterol & .036 & .068 & .030 & .533 & .595 \\
\hline 9. Self-service & -.112 & .068 & -.094 & -1.655 & .099 \\
\hline
\end{tabular}

a Dependent Variable: Fast food helps me to energize whenever I study.

* Significant

\subsubsection{Prefer Fast Food whenever they are Out of Home}

Second regression analysis was run between the preference factors of the students and the preference of the fast food when the students are out of their home. The analysis revealed that the nine factors can explain up to 9.3 percent of this dependent variable (Table 7.14).

Table 7.14 Model Summary

\begin{tabular}{|c|c|c|c|c|}
\hline Model & R & R Square & Adjusted R Square & Std. Error of the Estimate \\
\hline 1 & $.304(\mathrm{a})$ & .093 & .058 & 1.027 \\
\hline
\end{tabular}
analysis 1, REGR factor score 6 for analysis 1, REGR factor score 5 for analysis 1, REGR factor score 4 for analysis 1 , REGR factor score 3 for analysis 1, REGR factor score 2 for analysis 1, REGR factor score 1 for analysis 1

Table 7.15 shows that the preference factors related to the fast food choice of the students are as a whole significantly related to the preference of the fast food when the students are out of their home.

Table 7.15 ANOVA (b)

\begin{tabular}{|c|c|c|c|c|c|c|}
\hline Model & & Sum of Squares & df & Mean Square & F & Sig. \\
\hline 1 & Regression & 25.694 & 9 & 2.855 & 2.708 & $.005(\mathrm{a})$ \\
\hline & Residual & 251.968 & 239 & 1.054 & & \\
\hline & Total & 277.663 & 248 & & & \\
\hline
\end{tabular}

a Predictors: (Constant), REGR factor score 9 for analysis 1 , REGR factor score 8 for analysis 1 , REGR factor score 7 for analysis 1 , REGR factor score 6 for analysis 1 , REGR factor score 5 for analysis 1 , REGR factor score 4 for analysis 1 , REGR factor score 3 for analysis 1 , REGR factor score 2 for analysis 1 , REGR factor score 1 for analysis 1 $b$ Dependent Variable: I prefer fast food whenever I am out of home.

Table 7.16 shows that the factors such as, brand reputation and discount and taste are the significant factors. This means that these factors have significant relationship with the preference of fast food by the students whenever they are out of their homes. This means that brand reputation and discount and taste induces the students to consume fast food when they are out of their home. 
Table 7.16 Coefficients (a)

\begin{tabular}{|l|c|c|c|c|c|}
\hline & \multicolumn{2}{|c|}{$\begin{array}{c}\text { Unstandardized } \\
\text { Coefficients }\end{array}$} & $\begin{array}{c}\text { Standardized } \\
\text { Coefficients }\end{array}$ & t & Sig. \\
\hline & B & Std. Error & Beta & & \\
\hline (Constant) & 3.337 & .065 & & 51.289 & .000 \\
\hline 1. Brand reputation & .157 & .065 & .148 & 2.409 & $.017 *$ \\
\hline 2. Nearness and accessibility & .019 & .065 & .018 & .296 & .767 \\
\hline 3. Similarity in taste & .065 & .065 & .061 & .996 & .320 \\
\hline 4. Cost and quality relationship & .063 & .065 & .060 & .972 & .332 \\
\hline 5. Discount and Taste & .192 & .065 & .182 & 2.949 & $.004 *$ \\
\hline 6. Clean and Hygiene & .056 & .065 & .053 & .855 & .393 \\
\hline 7. Salesmanship and Decoration & .090 & .065 & .085 & 1.373 & .171 \\
\hline 8. Fat and Cholesterol & -.109 & .065 & -.103 & -1.664 & .097 \\
\hline 9. Self-service & -.102 & .065 & -.097 & -1.569 & .118 \\
\hline
\end{tabular}

a Dependent Variable: I prefer fast food whenever I am out of home. * Significant

\subsubsection{Fast Foods are Good for Lifestyle}

Third regression analysis was run between the preference factors of the students and good impact of fast food on the students' lifestyle. The analysis revealed that the nine factors can explain up to 18.5 percent of the dependent variable (Table 7.17).

Table 7.17 Model Summary

\begin{tabular}{|c|c|c|c|c|}
\hline Model & R & R Square & Adjusted R Square & Std. Error of the Estimate \\
\hline 1 & $.430(\mathrm{a})$ & .185 & .154 & .967 \\
\hline
\end{tabular}

a Predictors: (Constant), REGR factor score 9 for analysis 1, REGR factor score 8 for analysis 1, REGR factor score 7 for analysis 1, REGR factor score 6 for analysis 1, REGR factor score 5 for analysis 1, REGR factor score 4 for analysis 1 , REGR factor score 3 for analysis 1, REGR factor score 2 for analysis 1, REGR factor score 1 for analysis 1

Table 7.18 shows that the preference factors related to the positive impact of fast food on the students' lifestyle are as a whole significantly related to the preference of the fast food when the students are out of their home.

Table 7.18 ANOVA (b)

\begin{tabular}{|c|c|c|c|c|c|c|}
\hline Model & & Sum of Squares & df & Mean Square & F & Sig. \\
\hline 1 & Regression & 50.575 & 9 & 5.619 & 6.015 & $.000(\mathrm{a})$ \\
\hline & Residual & 223.280 & 239 & .934 & & \\
\hline & Total & 273.855 & 248 & & & \\
\hline
\end{tabular}

a Predictors: (Constant), REGR factor score 9 for analysis 1, REGR factor score 8 for analysis 1 , REGR factor score 7 for analysis 1, REGR factor score 6 for analysis 1, REGR factor score 5 for analysis 1, REGR factor score 4 for analysis 1 , REGR factor score 3 for analysis 1, REGR factor score 2 for analysis 1, REGR factor score 1 for analysis 1 $b$ Dependent Variable: I believe that fast foods are good for my lifestyle.

Table 7.19 shows that the factors such as, nearness and accessibility and cost and quality relationship are the significant factors. This means that these factors have significant relationship with the lifestyle of the students. 
Table 7.19 Coefficients (a)

\begin{tabular}{|l|c|c|c|c|c|}
\hline & \multicolumn{2}{|c|}{$\begin{array}{c}\text { Unstandardized } \\
\text { Coefficients }\end{array}$} & $\begin{array}{c}\text { Standardized } \\
\text { Coefficients }\end{array}$ & Sig. \\
\hline & B & Std. Error & Beta & & \\
\hline (Constant) & 3.024 & .061 & & 49.371 & .000 \\
\hline 1. Brand reputation & .030 & .061 & .029 & .491 & .624 \\
\hline 2. Nearness and accessibility & .228 & .061 & .217 & 3.710 & $.000^{*}$ \\
\hline 3. Similar taste of fast food & .066 & .061 & .063 & 1.070 & .286 \\
\hline 4. Cost and quality relationship & .342 & .061 & .326 & 5.577 & $.000^{*}$ \\
\hline 5. Discount and Taste & .092 & .061 & .087 & 1.494 & .137 \\
\hline 6. Clean and Hygiene & -.097 & .061 & -.092 & -1.579 & .116 \\
\hline 7. Salesmanship and Decoration & .090 & .061 & .086 & 1.467 & .144 \\
\hline 8. Fat and Cholesterol & .025 & .061 & .024 & .403 & .687 \\
\hline 9. Self-service & -.056 & .061 & -.054 & -.920 & .359 \\
\hline
\end{tabular}

a Dependent Variable: I believe that fast foods are good for my lifestyle. * Significant

\subsection{Revised Model of Consumers' Preferences on Fast Food Items}

Our study conforms to the consumer preference model for taking fast food items. It omits and introduces several factors from the conceptual model that is unique to the situation of Bangladeshi fast food market. The revised model for the choice of fast food by the university students is shown in Figure 3.

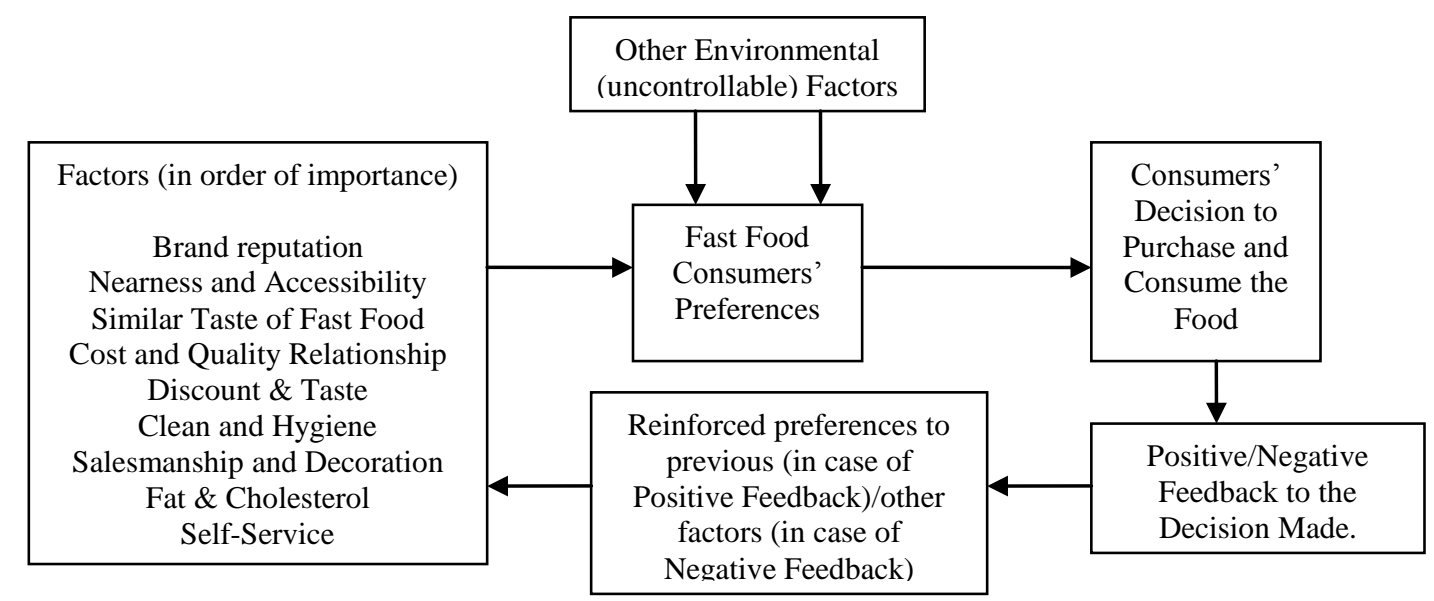

Figure-3: A Model of the Factors Influencing the Consumers of Fast Food Items in Bangladesh

This study identified that brand reputation is the most important factor of the student consumers of fast food in Bangladesh followed by nearness and accessibility, similar taste of fast food, cost and quality relationship, discount and taste, clean and hygiene, salesmanship and decoration, fat and cholesterol, and self-service. Factor analyses identified nine factors that are related to the consumers' preferences related to fast food selection by the students in Bangladesh. Brand reputation is the most important factor of the fast food consumers in Bangladesh followed by nearness and accessibility, similar taste of fast food, cost and quality relationship, discount and taste, clean and hygiene, salesmanship and decoration, fat and cholesterol, and self-service. Brand reputation of the fast food is number one factor used by the students in selecting the fast food items. Regression analysis between the factors identified through factor analysis and the energy impact of fast food identified that the factors related to students' preferences have about 23 percent impact on the energy of the students. The preference factors related to the fast food choice of the students are as a whole significantly related to the overall energizing capacity of the fast food. The factors like brand reputation, nearness and accessibility, similar taste of fast food, and cost and quality relationship are the significantly related to the energy impact of fast food. This means that the factors have 
significant relationship with the energy gained by the students by consuming fast food. Regression analysis between the preference factors of the students and the preference of the fast food when they are out of their home shows that the preference factors are as a whole significantly related to the preference of the fast food. The factors such as, brand reputation and discount and taste are the significant factors in this regard. This means that the factors have significant relationship with the preference of fast food of the students whenever they are out of their houses. This also indicates that brand reputation, discount, and taste induce the students to consume fast food when they are out of their home. Regression analysis between the preference factors of the students and good impact of fast food on the students' lifestyle were also performed. The preference factors related to the positive impact of fast food on the students' lifestyle are as a whole significantly related to the preference of the fast food when the students are out of their home. The factors such as, nearness and accessibility, and cost and quality relationship are the significant factors in this regard. This means that the factors have significant relationship with the lifestyle of the students.

\section{Conclusions and Recommendations}

Fast food consumers of Bangladesh, especially the university students, considered brand reputation as the most important factor when choosing fast foods followed by nearness and accessibility, similarity in taste, cost and quality relationship, discount and taste, clean and hygiene, salesmanship and decoration, fat and cholesterol, and self-service. The recent upset in the fast food industry of Bangladesh was created by the discovery of unethical practices conducted by several fast food businesses resulted in consumers putting their trusts on renowned fast food brands only. Thereby it is seen that the fast food houses with reputed brand name and recognition i.e. KFC, BFC, Pizza Hut, Coopers etc. are carrying out their businesses in a usual manner even in the toughest time of the industry. The majority of the fast food brands that passed with flying colors during the mobile courts inspection for quality maintenance were able to either establish or revitalize their brand reputation. Eventually as suggested by the research findings, the university students will select such fast food brands that have brand reputation.

Besides the brand reputation, the other important factors were nearness and accessibility, similar taste of fast food, cost and quality relationship, discount and taste. Incase of nearness or proximity and accessibility factor, consumers prefer to go to the fast food outlets that are close from their own home or study institutions. It is seen that the fast food shops in Bangladesh has already considering the factors by establishing their outlets near big corporate houses and private universities. Especially, in Dhaka city this practice is seen in Bailey road where majority of fast food shops are located. Near Bailey road, there are 3 girls' school and collages, and 3 boys' school and 2 collages in walking distance. Almost similar situation prevails in Gulshan Banani area of the city where KFC and Pizza Hut outlets are situated near 3 private universities. It is understandable from the situation that the students studying at these institutions consider these nearby fast food outlets whenever they decide to consume fast foods. There is an opportunity here however, for new fast food shops to compete with the existing fast food outlets. Since establishing a new outlet in an already competitive business space is expensive and difficult, the new fast food businesses can introduce mobile fast food outlets. Through mobile fast food outlets, new fast food businesses can deliver their fast foods that are already cooked fresh in their shops, but kept hot and delivered to the students instantly with their own choice of accompanying taste enhancers i.e. tomato sauce, cheese etc. These mobile fast food outlets could be on top of a mini-truck, van etc.

The similar taste of the fast food factor refers to the fact that no matter which fast food outlet a particular fast food item is bought from, the taste should be similar. For example, if a chicken burger is bought from an outlet of KFC, the taste would be similar to any other chicken burger bought from any other KFC outlet. The taste could differ from other fast food shops as the different business use taste as differentiating factor incase of food items. But the businesses have to keep in mind that too much difference in taste of similar fast food items makes the consumers confused.

The cost and quality relationship is also an important factor considered by the consumers of fast food. If the cost of a fast food item is high, it is usually considered to be carrying high quality and vice versa. So, the businesses of fast food products have to be careful in setting the prices of the fast food items. The pricing should be such as it offers the right amount to value to the consumers in a competitive price that at the same time ensures adequate profit margins for the fast food businesses. 
Finally in terms of discount and taste factor, the consumers consider the availability of discounts in fast food outlets. Usually these discounts are offered as group discounts i.e. arranging a party or social gathering at a reduced price package etc. Consumers consider this option when choosing fast food products. They might not immediately use this factor but it puts the fast food shop in their consideration set for later use.

This study recommends that the fast food producers or distributors at Dhaka city should focus more on the brand reputation, nearness or proximity and accessibility, cost, quality, discount, and similarity in taste factors. If they are able to fulfill these needs, university students of Bangladesh will be induced to buy and consume fast food whenever they are out of their houses. However, there is an ample scope to conduct further study on the preference factors used by the office-goers, housewives, and visitors in buying fast food to determine if there are any more common or unique factors prevailing among these different groups that might be important in making decisions regarding the choice of fast food items in Bangladesh.

\section{REFERENCES}

1. Auty, S. 1992. Consumer choice and segmentation in the restaurant industry. Serv. Indust. J. 12(3), 324339.

2. BAREHAM, J. 1995. Consumer Behavior in the Food Industry. A European Perspective, ButterworthHeinemann, Oxford, U.K.

3. Binkley, James K. (2008), Calorie and Gram Differences between Meals at Fast Food Table Service Restaurants, Review of Agricultural Economics, Volume 30, Number 4-Pages 750-763

4. Bowman, Shanthy A., Steven L. Gortmaker, PhD; Cara B. Ebbeling, PhD; Mark A. Pereira, PhD; and David S. Ludwig, MD, PhD (2004) Effects of Fast-Food Consumption on Energy Intake and Diet Quality Among Children in a National Household Survey, PEDIATRICS Vol. 113 No. 1 January 2004

5. Buttle, F. 1986. Hotel and Food Service Marketing - A Managerial Approach, pp. 76-191, Cassell Educational, London, England.

6. Clark, M. and Wood, C.R 1998. Consumer loyalty in the restaurant industry: A preliminary exploration of the issues. Int. J. Contemporary Hospit. Mgmt. 10(4), 139-144.

7. Carey, R.A. and Genevieve, L. 1995. USA snapshots: Factors influencing choice of sit-down restaurant. USA Today, June 23, p. D1.

8. Kuchler,F.,E. Golan, J.N.Variyam, and S.R. Crutch-field. 2005. Obesity Policy and the Law of Unintended Consequences. Amber Waves 3:26-33.

9. Lawrence, J. M., E. Devlin, S. Macaskill, M. Kelly, M. Chinouya, M. M. Raats, K. L. Barton, W. L. Wrieden \& R. Shepherd (2007) Factors that affect the food choices made by girls and young women, from minority ethnic groups, living in the UK. The British Dietetic Association Ltd 2007 J Hum Nutr Diet, 20, pp. 311-319

10. Lewis, C.R 1981. Restaurant advertising: Appeals and consumer intentions. J. Advert. Res. 21(5), 69-74.

11. Lin, B.H., J. Guthrie, and E. Frazao. "Nutrient Contribution of Food Away from Home." America's Eating Habits: Changes and Consequences. Washington, DC: USDA Economic Research Service Bulletin AIB750, May 1999

12. Maxwell, D., Larbe, W., Lamptey, G., Zakariah, S. \& Armar-Klemesu, M. 1998. Farming in the Shadow of the City: Changes in Land Rights and Livelihoods in Peri-Urban Accra. Cities Feeding People Report 23, International Development Research Centre (available at http://web.idrc.ca/en).

13. Prentice, A. M. and Jebb, S. A. (2003) Fast foods, energy density and obesity: a possible mechanistic link. The International Association for the Study of Obesity. Obesity Reviews 187-194

14. Pingali, P. \& Khwaja, Y. 2004 Westernization of Asian diets and the transformation of food systems: Implications for research and policy. (mimeo)

15. Popkin, B. 2002. The dynamics of the dietary transition in the developing world. In: B. Caballero \& B. Popkin, eds. The Nutrition Transition: Diet and Disease in the Developing World, pp. 111-128. London, Academic Press.

16. Richards, Timothy j. and Padilla, Luis (2009) Promotion and Fast Food Demand. Amer. J. Agr. Econ. 91(1) (February 2009): 168-183 
17. Smil, V. 2000. Feeding the World - A Challenge for the Twenty-First Century. Cambridge, MA, and London, England, MIT Press.

18. Stamoulis, Kostas G., Pingali, Prabhu and Shetty, Prakash; Emerging Challenges for Food and Nutrition Policy in Developing Countries, Vol. 1, No. 2, 2004, pp. 154-167

19. Turley, L.W., Milliman, R.E. (2000), "Atmospheric Effects on Shopping Behavior: A Review of the Experimental Evidence", Journal of Business Research, Vol. 49 No.2, pp.193-211.

20. United Nations Population Fund (UNFPA) 2001. The State of World Population 2001 (available at http://www.unfpa.org/swp/2001/english).

\section{FOOTNOTES}

1. http://www.merriam-webster.com/dictionary/fast\%20food

2. The Evolution of the Quick Service Restaurant". A Management Consultant @ Large. http://jpfarrell.blogspot.com/2007/11/evolution-of-quick-service-restaurant.html. Retrieved on 2008-02-10.

3. $\quad$ http://en.wikipedia.org/wiki/Fast food restaurant\#cite note-2

4. $\quad$ http://www.hoovers.com/fast-food-and-quickservice-restaurants/--ID 269--/free-ind-fr-profilebasic.xhtml

5. $\quad$ http://www.wikinvest.com/industry/Fast_Food_Restaurants_QSR

6. Schlosser, Eric, "Fast-Food Nation: The True Cost Of America's Diet", Rolling Stone magazine (USA), Issue 794, September 3rd 1998

7. "Fast Food: Global Industry Guide to their offering", http://www.researchandmarkets.com/reports/c71910)

8. http://transcom.com.bd/?page_id=28

9. The Daily Star, Vol. 5 Num 455 Mon. September 05, 2005

10. Star Lifestyle Volume 3, Issue 21, Tuesday December 27, 2005

11. The Daily Star, Vol. 5 Num 442, August 23, 2005

12. The New Nation, Internet Edition, March 9, 2008

13. Star Lifestyle, Volume 1, Issue 26, Tuesday November 25, 2003 


\section{Appendices}

Table 7.4 Similar Taste of Fast Food

Variables

My favorite fast food item purchased from any fast food shop offers me the same tastes.

I go to the fast food shops that my friends like but I don't.

I consume the fast food items that my friends like but I don't.

I prefer the fast food shops that are located in the busiest areas of Dhaka city.

I consider the food values of the fast food items I regularly consume.

\begin{tabular}{|c|}
\hline Factor loading \\
.689 \\
.686 \\
.675 \\
.422 \\
\hline .417 \\
\hline
\end{tabular}

Table 7.5 Cost and Quality Relationship

\begin{tabular}{|l|c|}
\hline \multicolumn{1}{|c|}{ Variables } & Factor loading \\
\hline Costlier fast foods offer better quality. & .745 \\
\hline Price of mine favorite fast food is acceptable to me. & .720 \\
\hline Quick delivery of the item I order in a fast food shop is important to me. & .498 \\
\hline I like the fast food shops that manage the long cues efficiently. & .497 \\
\hline
\end{tabular}

Table 7.6 Discount and Taste

\begin{tabular}{|l|c|}
\hline \multicolumn{1}{|c|}{ Variables } & Factor loading \\
\hline I go to the fast food shops that offer group discounts. & .733 \\
\hline My favorite fast food item offers a unique taste to me. & .625 \\
\hline
\end{tabular}

Table 7.7 Clean and Hygiene

\section{Variables}

Fast food outlets with clean hygiene records are more preferred by me.

I prefer the fast food shops that use fresh ingredients everyday.

I prefer the fast foods that are most tasty.

Factor loading .581

.532

.511

Table 7.8 Salesmanship and Decoration

Variables

I prefer the fast food shops that have smart personnel working.

I consider the lighting, decoration etc. of the fast food shops before revisiting them.

Factor loading

.816

.499

Table 7.9 Fat and Cholesterol

Variable

I avoid the fast food items that carry the most fat and cholesterol.

Table 7.10 Self-service

I prefer the fast food shops with self service.
Factor loading .697 


\section{Appendix 1 Communalities of the variables}

\begin{tabular}{|c|c|}
\hline & Extraction \\
\hline Quick delivery of the item I order in a fast food shop is important to me. & .577 \\
\hline I like the fast food shops that manage the long cues efficiently. & .556 \\
\hline Price of mine favorite fast food is acceptable to me. & .565 \\
\hline Costlier fast foods offer better quality. & .616 \\
\hline Fast food outlets with clean hygiene records are more preferred by me. & .478 \\
\hline Clean packaging of the fast food is important to me. & .486 \\
\hline The service people present in the fast food shop is important to me. & .489 \\
\hline I prefer the fast food shops that use fresh ingredients everyday. & .596 \\
\hline I avoid fast food shops that have past records of using hazardous materials in their products. & .645 \\
\hline I prefer the fast food shops that are close to my university. & .622 \\
\hline I prefer the fast food shops that are easily accessible from anywhere in Dhaka city. & .650 \\
\hline I prefer the fast food shops that offer privacy. & .560 \\
\hline I prefer the fast food shops that are located in the busiest areas of Dhaka city. & .583 \\
\hline My favorite fast food item offers a unique taste to me. & .447 \\
\hline My favorite fast food item purchased from any fast food shop offers me the same tastes. & .617 \\
\hline I do not consume my favorite fast food item if it does not taste right to me. & .370 \\
\hline I prefer items from well known fast food shops to little known fast food shops. & .590 \\
\hline Even though I do not like the food, I like to go to the well reputed fast food shops. & .639 \\
\hline I am willing to try new fast food items only from well reputed fast food shops. & .652 \\
\hline I will buy any fast food from well reputed fast food shops. & .661 \\
\hline I go to the fast food shops that offer group discounts. & .604 \\
\hline I consume the fast food items that my friends like but I don't. & .726 \\
\hline I go to the fast food shops that my friends like but I don't. & 639 \\
\hline I consider the food values of the fast food items I regularly consume. & .549 \\
\hline I prefer the fast foods that are most tasty. & .548 \\
\hline I avoid the fast food items that carry the most fat and cholesterol. & .624 \\
\hline I avoid the tasty fast food items that do not suite my stomach. & .597 \\
\hline I prefer the fast food shops that have smart personnel working. & .692 \\
\hline I consider the lighting, decoration etc. of the fast food shops before revisiting them. & .497 \\
\hline I prefer the fast food shops with self service. & .619 \\
\hline
\end{tabular}

\section{Extraction Method: Principal Component Analysis}

